\title{
Drug resistance of pathogens causing nosocomial infection in orthopedics from 2012 to 2017: a 6-year retrospective study
}

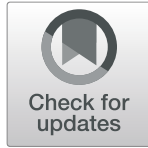

Xiaowei Yang ${ }^{1 \dagger}$, Runsheng Guo ${ }^{1 \dagger}$, Banglin Xie ${ }^{1 \dagger}$, Qi Lai ${ }^{1}$, Jiaxiang Xu' ${ }^{1}$ Niya Hu², Lijun Wan ${ }^{1}$, Min Dai ${ }^{1}$ and Bin Zhang ${ }^{1^{*}}$

\begin{abstract}
Background: Hospital-acquired infections (HAls) are an emerging global problem that increases in-hospital mortality, length of stay, and cost. We performed a 6-year retrospective study to provide valuable insight into appropriate antibiotic use in HAl cases. We also aimed to understand how hospitals could reduce pathogen drug resistance in a population that overuses antibiotics.
\end{abstract}

Methods: All data (2012-2017) were obtained from the hospital information warehouse and clinical microbiology laboratory.

Results: We isolated 1392 pathogen strains from patients admitted to the orthopedics department during 20122017. Escherichia coli (14.7\%, 204/1392), Enterobacter cloacae (13.9\%, 193/1392), and Staphylococcus aureus (11.3\%, 157/1392) were the most common pathogens causing nosocomial infections. The dominant Gram-negative bacterium was E. coli, with high resistance to ampicillin, levofloxacin, cotrimoxazole, gentamicin, and ciprofloxacin, in that order. E. coli was least resistant to amikacin, cefoperazone-sulbactam. The most dominant Gram-positive bacterium was $S$. aureus, highly resistant to penicillin and ampicillin, but not resistant to fluoroquinolones and cotrimoxazole. Analysis of risk factors related to multidrug-resistant bacteria showed that patients with open fractures (Gustillo III B and IIIC) were significantly more susceptible to methicillin-resistant S. aureus infections ( $p<$ 0.05). Additionally, extended-spectrum $\beta$-lactamase-producing $E$. coli infections occurred significantly more often in patients with degenerative diseases $(p<0.05)$. Elderly patients tended to be more susceptible to multidrug-resistant bacterial infections, but this outcome was not statistically significant.

Conclusions: Antimicrobial resistance is a serious problem in orthopedics. To effectively control antimicrobial resistance among pathogens, we advocate extensive and dynamic monitoring of MDR bacteria, coupled with careful use of antibiotics.

Keywords: Hospital-acquired infections, Orthopedics, Drug resistance, Multidrug resistance

\footnotetext{
* Correspondence: yxwzb11@126.com

'Xiaowei Yang, Runsheng Guo and Banglin Xie contributed equally to this work.

'Department of Orthopedics, First Affiliated Hospital of Nanchang University, No. 17 Yong Wai Zheng Street, Nanchang 330006, Jiangxi, China Full list of author information is available at the end of the article
} 


\section{Background}

Hospital-acquired infections (HAIs), especially at surgical sites, are catastrophic complications that lead to higher in-hospital mortality, longer stay duration, and greater expense [1]. The USA alone spends over $\$ 33$ billion on HAIs per year [2]. With the rapid development of invasive medical devices, HAI contributions to surgery-related morbidity and mortality have increased considerably [3]. This effect is particularly noticeable in orthopedics, an area that is very reliant on implants (e.g., internal fixation devices for bone fractures), wound dressings, and catheters. A 9-year retrospective study on 90551 patients who underwent elective spine surgery discovered that surgical site and urinary tract infection rates were $1.4 \%$ and $1.3 \%$, respectively. Moreover, hospital stay duration was $1.48 \pm 0.04$ days longer and the cost was $\$ 8893 \pm \$ 148$ greater for patients with HAIs [4]. Similarly, surgical site infections are the most common $(25.2 \%)$ and the third most common (14.8\%) reason for revision total knee arthroplasty and revision total hip arthroplasty, respectively [5].

Compounding HAI-related issues, antibiotic resistance among pathogens is a serious problem, owing to drug abuse stemming from hospital over-prescription as well as excessive self-medication in Chinese communities [6]. Furthermore, multidrug-resistant (MDR) bacteria have become increasingly prevalent, with notable examples being methicillin-resistant Staphylococcus aureus (MRSA) and extended-spectrum $\beta$-lactamase (ESBL)positive Escherichia coli [7]. One study found that the MRSA isolation rate from patients ranges from 42.1 to $69.5 \%$ [8], which is very high despite a decreasing trend over 6 years. Likewise, another report isolated $30-40 \%$ MRSAs and 20-30\% ESBL-positive E. coli [9]. The presence of MRSA or ESBL-positive E. coli in patients is associated with increased mortality $[10,11]$.

Most of the studies on pathogen resistance in orthopedics focused only on microbes causing surgical wound infections. However, HAIs are increasingly recognized as a major factor exacerbating such infections [12]. Therefore, this study aimed to understand resistance patterns of HAI-inducing microbes commonly found in orthopedics. Our findings should benefit efforts to encourage conservative antibiotic use when HAIs occur and to reduce pathogen drug resistance.

\section{Methods}

\section{Location and study design}

The department of orthopedics of the First Affiliated Hospital of Nanchang University has six wards and 350 beds, divided into seven sub-specialties: trauma, spine, joint, sports medicine, bone tumor and bone disease, and hand and foot microscopic repair and reconstruction, as well as pediatric orthopedics. Over 10,000 surgeries are performed annually, of which 60\% are levels III and IV. Sickbed utilization rate is greater than $130 \%$.

A retrospective surveillance study (2012-2017) was performed on nosocomial infections in orthopedics. Data were obtained from the hospital information warehouse and clinical microbiology laboratory. Nosocomial infections are defined as infections that begin when a patient is residing in a hospital, but were absent at the time of admission [13]. Here, we specifically classified infections as nosocomial if they occurred $48 \mathrm{~h}$ post-admission/ post-surgery or later. Two researchers collected all relevant data, including basic patient information, bacteria strains cultivated, and antimicrobial resistance.

\section{Strain identification and antibiotic sensitivity testing}

All clinical specimens, including wound secretions (skin and tissue that were already injured pre-surgery), incisional secretions (skin and tissue intact pre-surgery), urine, blood, and joint fluids, obtained from the orthopedics department between January 2012 and December 2017 were included in the analysis if they tested positive for pathogens. Identical strains from the same patient were excluded. Within $2 \mathrm{~h}$ of collection, specimens were stored in sterile culture tubes and sent to the microbiology laboratory. Different bacterial strains and antibacterial sensitivity were identified using the VITEK-2 automated system (bioMérieux Inc., France). Antimicrobial susceptibility was tested with the Kirby-Bauer method and minimum inhibitory concentrations, following updated guidelines from the Clinical and Laboratory Standards Institute [14]. S. aureus and E. coli were routinely tested with fourteen antibiotics, which are shown in Tables 2 and 3. S. aureus ATCC29213 and E. coli ATCC25922 strains were used in the antimicrobial susceptibility tests for quality control. Phenotypic confirmatory tests for extended-spectrum $\beta$-lactamase (ESBL)producing $E$. coli and methicillin-resistant $S$. aureus (MRSA) were performed according to the latest CLSI guidelines [14].

\section{Statistical analysis}

Antibiotic susceptibility data were analyzed using WHONET 5.6. Chi-square tests were used to determine between-group differences and for trend analysis. All analyses were performed in SPSS 23.0 (SPSS Inc., Chicago, IL, USA). Significance was set at $p<0.05$.

\section{Results}

\section{Pathogen distribution in orthopedics patients}

Among the 1392 pathogen strains isolated from patients (Fig. 1a), 399 (28.7\%) were Gram-positive, 982 (70.5\%) were Gram-negative, and $11(0.8 \%)$ were fungi. Additionally, 547 strains (39.3\%) were recovered from wound 


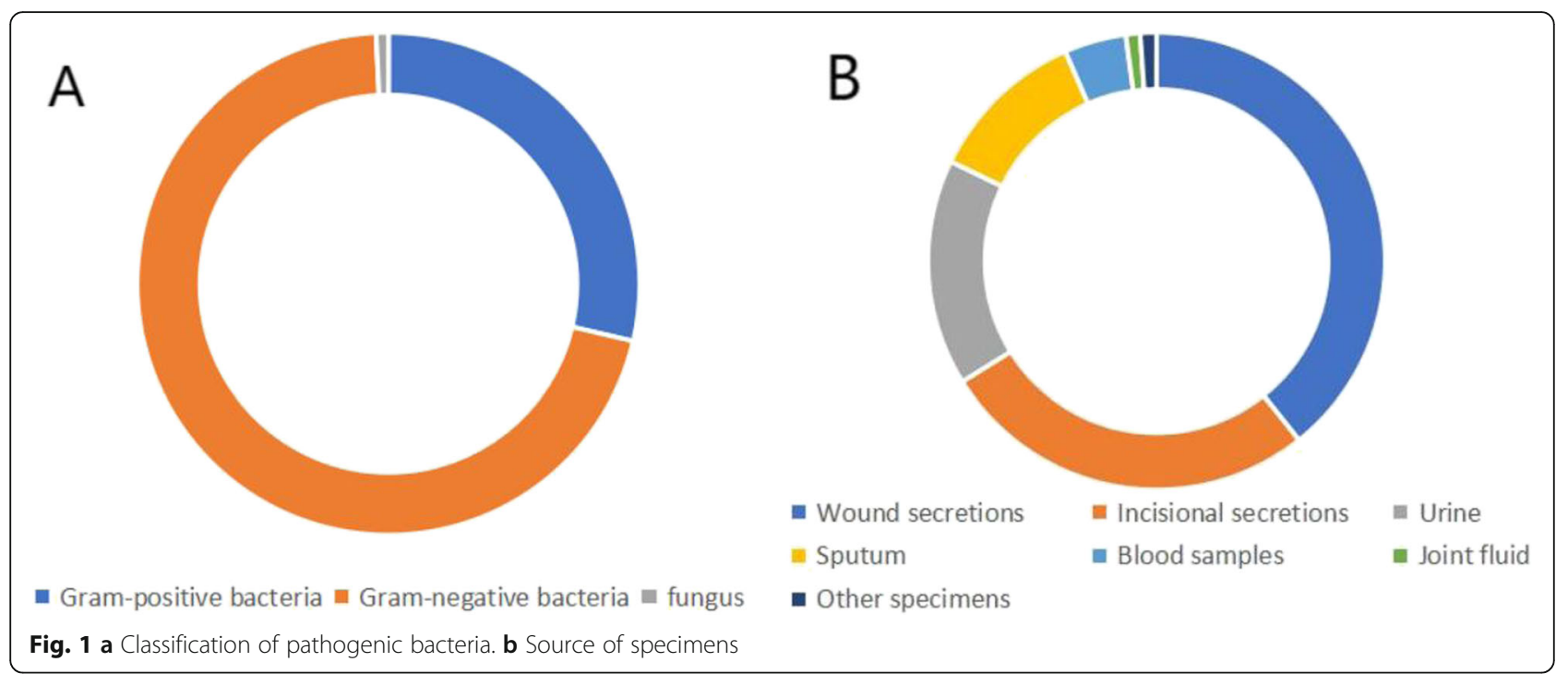

secretions; 374 (26.9\%) from incisional secretions; 223 (16.0\%) from urine; 157 (11.3\%) from sputum; 61 (4.4\%) from blood; 14 (1\%) from joint fluids; and 16 (1.1\%) from other specimens (Fig. 1b). During the 6-year period (Table 1), E. coli $(14.7 \%, 204 / 1392)$ was the most common pathogen responsible for nosocomial infection, followed by Enterobacter cloacae (13.9\%, 193), S. aureus (11.3\%, 157), Pseudomonas aeruginosa (9.8\%, 136), Acinetobacter baumannii $(9.6 \%, 134)$, Staphylococcus epidermidis $(6.5 \%, 90)$, Klebsiella pneumoniae $(4.6 \%, 64)$, and Enterococcus faecalis $(3.2 \%, 44)$.

\section{Drug resistance rate of major pathogens}

The dominant Gram-negative and Gram-positive bacteria causing nosocomial infections were respectively E. coli and S. aureus. Almost all S. aureus strains were resistant to penicillin (90.9-100\%) and ampicillin (100\%); over half were resistant to oxacillin, ceftriaxone, and erythromycin (Table 2). Fewer strains were resistant to levofloxacin, ciprofloxacin, and cotrimoxazole. None was resistant to nitrofurantoin, linezolid, and vancomycin. Trend analysis showed that $S$. aureus resistance to tetracycline significantly decreased $(53.8 \%$ in 2012 and $37.5 \%$ in 2017, $p=0.026$ ), whereas resistance to amoxicillin-clavulanic acid rose (20\% in 2012 and 50\% in 2017, $p=0.035$ ).

Most E. coli strains (81.8-93.3\%) were resistant to ampicillin (Table 3). Approximately half were resistant to levofloxacin, ciprofloxacin, gentamicin, and cotrimoxazole (Table 3). Less than $20 \%$ of strains were resistant to amikacin, cefoperazone-sulbactam, meropenem, imipenem, and piperacillin-tazobactam. We observed a significant decrease in E. coli resistance to cotrimoxazole over time (47.1\% in 2012 and $36.4 \%$ in 2017, $p=0.042$ ), whereas resistance to imipenem and piperacillintazobactam significantly increased.

Table 1 Strains isolated from patients with HAls from 2012 to 2017

\begin{tabular}{llllllll}
\hline & $\mathbf{2 0 1 2}$ & $\mathbf{2 0 1 3}$ & $\mathbf{2 0 1 4}$ & $\mathbf{2 0 1 5}$ & $\mathbf{2 0 1 6}$ & $\mathbf{2 0 1 7}$ & Total \\
\hline E. coli & $38(15.1 \%)$ & $39(17.8 \%)$ & $36(18.3 \%)$ & $40(15 \%)$ & $29(11.8 \%)$ & $22(10.4 \%)$ & 204 \\
E. cloacae & $40(15.9 \%)$ & $33(15.1 \%)$ & $18(9.1 \%)$ & $28(10.5 \%)$ & $34(13.8 \%)$ & $40(18.9 \%)$ & 193 \\
S. aureus & $28(11.1 \%)$ & $28(12.9 \%)$ & $33(16.8 \%)$ & $28(10.5 \%)$ & $24(9.8 \%)$ & $16(7.5 \%)$ & 157 \\
P. aeruginosa & $28(11.1 \%)$ & $17(7.8 \%)$ & $23(11.7 \%)$ & $26(9.8 \%)$ & $22(8.9 \%)$ & $20(9.4 \%)$ & 136 \\
A. baumannii & $22(8.7 \%)$ & $24(11 \%)$ & $16(8.1 \%)$ & $24(9.0 \%)$ & $24(9.8 \%)$ & $24(11.3 \%)$ & 134 \\
S. epidermidis & $16(6.3 \%)$ & $14(6.4 \%)$ & $13(6.6 \%)$ & $15(5.6 \%)$ & $16(6.5 \%)$ & $16(7.5 \%)$ & 90 \\
K. pneumoniae & $12(4.8 \%)$ & $10(4.6 \%)$ & $9(4.6 \%)$ & $13(4.9 \%)$ & $10(4.1 \%)$ & $10(4.7 \%)$ & 64 \\
E. faecalis & $8(3.2 \%)$ & $6(2.7 \%)$ & $7(3.6 \%)$ & $9(3.4 \%)$ & $8(3.3 \%)$ & $6(2.8 \%)$ & 44 \\
The others & 60 & 48 & 42 & 83 & 79 & 248 & 370 \\
Total & 252 & 219 & 197 & 266 & 212 & 1392 \\
\hline
\end{tabular}


Table 2 Trend of drug resistance rate of S. aureus in orthopedics from 2012 to 2017

\begin{tabular}{|c|c|c|c|c|c|c|c|c|}
\hline \multirow[t]{2}{*}{ Antibiotics } & \multicolumn{6}{|c|}{ Drug resistance rate [\%(strains/strains)] } & \multicolumn{2}{|l|}{ Value } \\
\hline & 2012 & 2013 & 2014 & 2015 & 2016 & 2017 & $x^{2}$ & $p$ \\
\hline Penicillin & $100.0(20 / 20)$ & $100.0(16 / 16)$ & $100.0(20 / 20)$ & $90.9(20 / 22)$ & $100.0(20 / 20)$ & $100.0(14 / 14)$ & --- & --- \\
\hline Oxacillin & $50.0(12 / 24)$ & $39.1(9 / 23)$ & $53.1(17 / 32)$ & $50.0(13 / 26)$ & $60.9(14 / 23)$ & $75.0(12 / 16)$ & 5.632 & 0.344 \\
\hline Amoxicillin-clavulanic acid & $20.0(4 / 20)$ & $37.5(6 / 16)$ & $59.1(13 / 22)$ & $60.9(14 / 23)$ & $66.7(12 / 18)$ & $50.0(8 / 16)$ & 12.006 & 0.035 \\
\hline Ceftriaxone & $\ldots$ & $50.0(8 / 16)$ & $52.4(11 / 21)$ & $47.8(11 / 23)$ & $73.7(14 / 19)$ & $75.0(12 / 16)$ & 5.488 & 0.241 \\
\hline Levofloxacin & $25.0(6 / 24)$ & $18.2(4 / 22)$ & $21.9(7 / 32)$ & $14.8(4 / 27)$ & $25.0(6 / 24)$ & $25.0(4 / 16)$ & 1.330 & 0.932 \\
\hline Tetracycline & $53.8(14 / 26)$ & $27.3(6 / 22)$ & $42.3(11 / 26)$ & $11.5(3 / 26)$ & $25.0(6 / 24)$ & $37.5(6 / 16)$ & 12.740 & 0.026 \\
\hline Ciprofloxacin & $33.3(8 / 24)$ & $18.2(4 / 22)$ & $33.3(11 / 33)$ & $14.8(4 / 27)$ & $25.0(6 / 24)$ & $25.0(4 / 16)$ & 4.104 & 0.535 \\
\hline Gentamicin & $41.2(12 / 26)$ & $20.0(4 / 20)$ & $25.0(8 / 32)$ & $16.7(4 / 26)$ & $45.8(11 / 24)$ & $37.5(6 / 16)$ & 10.161 & 0.071 \\
\hline Cotrimoxazole & $21.4(6 / 28)$ & $16.0(4 / 25)$ & $12.1(4 / 33)$ & $11.1(3 / 27)$ & $8.3(2 / 24)$ & $12.5(2 / 16)$ & 2.270 & 0.829 \\
\hline Ampicillin & $100.0(20 / 20)$ & $100.0(17 / 17)$ & $100.0(23 / 23)$ & $100.0(21 / 21)$ & $100.0(20 / 20)$ & $100.0(12 / 12)$ & --- & -- \\
\hline Erythromycin & $83.3(20 / 24)$ & $50.0(11 / 22)$ & $75.0(24 / 32)$ & $76.9(20 / 26)$ & $66.7(16 / 24)$ & $75.0(12 / 16)$ & 7.076 & 0.211 \\
\hline Nitrofurantoin & $0.0(0 / 14)$ & $0.0(0 / 6)$ & $0.0(0 / 6)$ & $0.0(0 / 5)$ & $0.0(0 / 6)$ & $0.0(0 / 7)$ & --- & --- \\
\hline Linezolid & $0.0(0 / 26)$ & $0.0(0 / 22)$ & $0.0(0 / 30)$ & $0.0(0 / 25)$ & $0.0(0 / 24)$ & $0.0(0 / 16)$ & --- & --- \\
\hline Vancomycin & $0.0(0 / 12)$ & $0.0(0 / 22)$ & $0.0(0 / 26)$ & $0.0(0 / 26)$ & $0.0(0 / 24)$ & $0.0(0 / 16)$ & --- & --- \\
\hline
\end{tabular}

...: Means that antibiotic was not tested or the results were not available in that year

---: Means that the chi-square value cannot be calculated

\section{Frequency of multidrug-resistant strains}

The proportion of MRSA isolates was 43.3\% (range: 28.6-62.5\%), and the proportion of ESBL-positive $E$. coli isolates was $74.2 \%$ (range: 63.6-79.5\%) (Fig. 2). exhibited a trend of increased susceptibility to MDR bacterial infections, but this effect was not significant. Finally, history of smoking and alcohol, diabetes, hypertension, and sex were not risk factors for infection with MDR bacteria.

\section{Risk factors linked to MDR bacteria}

Open fractures(Gustillo III B and IIIC) and degenerative diseases were significantly correlated with MDR bacterial infections $(p<0.05)$ (Table 4$)$. Elderly patients

\section{Discussion}

In our study, E. coli was the predominant pathogen, followed by $E$. cloacae, S. aureus, $P$. aeruginosa, and $A$.

Table 3 Trend of drug resistance rate of E. coli in orthopedics from 2012 to 2017

\begin{tabular}{|c|c|c|c|c|c|c|c|c|}
\hline \multirow[t]{2}{*}{ Antibiotics } & \multicolumn{6}{|c|}{ Drug resistance rate [\%(strains/strains)] } & \multicolumn{2}{|l|}{ Value } \\
\hline & 2012 & 2013 & 2014 & 2015 & 2016 & 2017 & $x^{2}$ & $p$ \\
\hline Amikacin & $16.7(4 / 24)$ & $8.8(3 / 34)$ & $3.0(1 / 33)$ & $10.5(4 / 38)$ & $10.7(3 / 28)$ & $0.0(0 / 22)$ & 5.651 & 0.311 \\
\hline Ceftazidime & $28.6(8 / 28)$ & $51.5(17 / 33)$ & $58.1(18 / 31)$ & $45.9(17 / 37)$ & $42.9(12 / 28)$ & $45.5(10 / 22)$ & 5.760 & 0.330 \\
\hline Cefepime & $26.7(8 / 30)$ & $33.3(11 / 33)$ & $48.5(16 / 33)$ & $48.6(18 / 37)$ & $42.9(9 / 21)$ & $\ldots$ & 5.033 & 0.284 \\
\hline Cefoxitin & $\ldots$ & $\ldots$ & $25.0(4 / 16)$ & $12.5(3 / 24)$ & $24.0(6 / 25)$ & $10.0(2 / 20)$ & 2.205 & 0.488 \\
\hline Levofloxacin & $53.3(16 / 30)$ & $51.5(17 / 33)$ & $51.5(17 / 33)$ & $36.8(14 / 38)$ & $60.7(17 / 28)$ & $63.6(14 / 22)$ & 5.558 & 0.352 \\
\hline Tobramycin & $27.3(6 / 22)$ & $23.5(8 / 34)$ & $25.0(6 / 24)$ & $28.6(10 / 35)$ & $28.6(8 / 28)$ & $36.4(8 / 22)$ & 1.226 & 0.942 \\
\hline Cefperazone-sulbactam & $7.1(2 / 28)$ & $3.0(1 / 33)$ & $8.3(2 / 24)$ & $0.0(0 / 17)$ & $10.5(2 / 19)$ & $10.0(2 / 20)$ & 3.139 & 0.709 \\
\hline Ciprofloxacin & $53.3(16 / 30)$ & $51.5(17 / 33)$ & $57.6(19 / 33)$ & $39.5(15 / 38)$ & $42.1(16 / 28)$ & $45.5(10 / 22)$ & 3.337 & 0.648 \\
\hline Gentamicin & $60.0(18 / 30)$ & $54.5(18 / 33)$ & $51.5(17 / 33)$ & $34.2(13 / 38)$ & $46.4(13 / 28)$ & $45.5(10 / 22)$ & 5.427 & 0.366 \\
\hline Cotrimoxazole & $47.1(16 / 34)$ & $67.6(23 / 34)$ & $75.8(25 / 33)$ & $57.1(20 / 35)$ & $57.1(16 / 28)$ & $36.4(8 / 22)$ & 11.493 & 0.042 \\
\hline Meropenem & $0.0(0 / 28)$ & $3.3(1 / 30)$ & $6.1(2 / 33)$ & $8.3(2 / 24)$ & $19.2(5 / 26)$ & $10.0(2 / 20)$ & 7.476 & 0.124 \\
\hline Imipenem & $6.7(2 / 30)$ & $2.9(1 / 34)$ & $3.0(1 / 33)$ & $0.0(0 / 38)$ & $17.9(5 / 28)$ & $9.1(2 / 22)$ & 9.130 & 0.043 \\
\hline Ampicillin & $93.3(28 / 30)$ & $97.0(33 / 34)$ & $93.8(30 / 32)$ & $91.9(34 / 37)$ & $92.9(26 / 28)$ & $81.8(18 / 22)$ & 4.108 & 0.530 \\
\hline Piperacillin-tazobactam & $0.0(0 / 30)$ & $2.9(1 / 34)$ & $3.0(1 / 33)$ & $0.0(0 / 38)$ & $17.9(5 / 28)$ & $18.2(4 / 22)$ & 14.370 & 0.010 \\
\hline
\end{tabular}

...: Means that antibiotic was not tested or the results were not available in that year

---: Means that the chi-square value cannot be calculated 


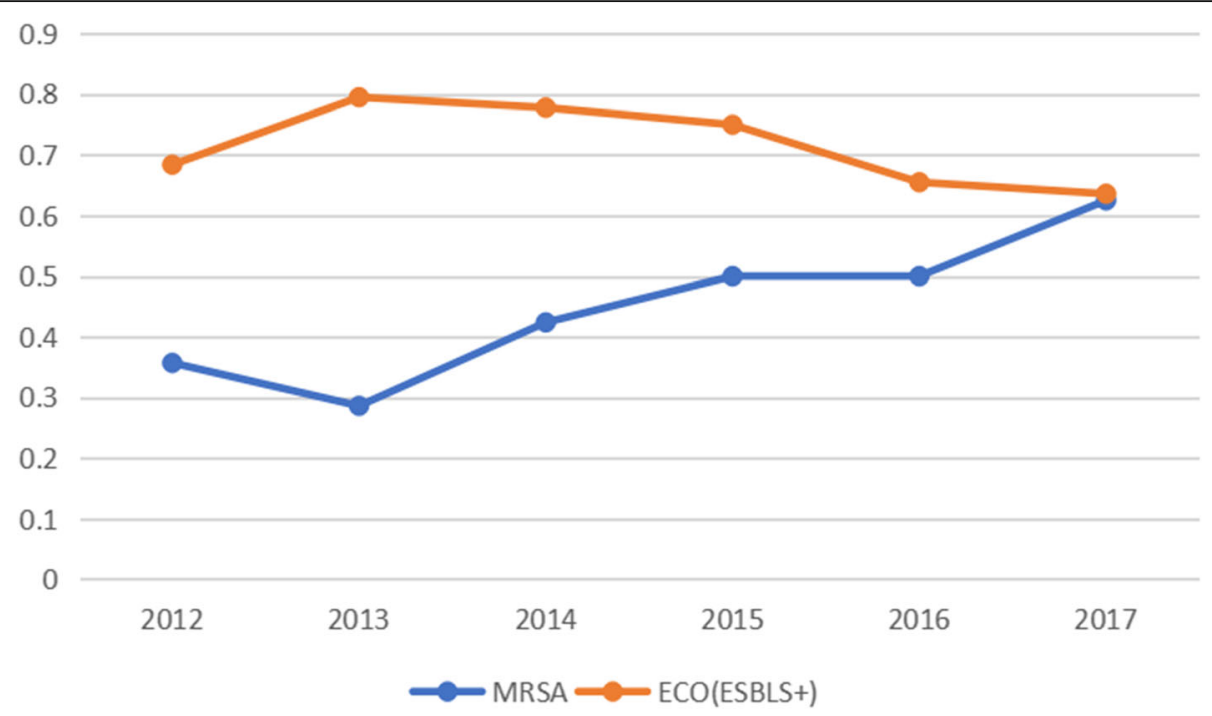

Fig. 2 Frequency of methicillin-resistant S. aureus (MRSA) and extended-spectrum $\beta$-lactamase (ESBL)-producing E. coli in orthopedics patients from 2012 to 2017

baumannii (9.6\%), similar to several previous findings $[15,16]$. However, a cross-sectional descriptive study found that $P$. aeruginosa was the predominant microorganism $(36.17 \%)$ causing nosocomial infections in orthopedics, whereas $E$. coli was only the fourth most prominent (6.38\%); E. cloacae and S. aureus were even rarer [17]. This apparent discrepancy is likely due to the different procedures and tissue samples. Sarker et al. [17] only surveyed pathogens isolated from incisional secretions, but here, we surveyed pathogens isolated from a much larger variety of samples. For example, $E$. coli and $S$. aureus were frequently found in non-

Table 4 Demographic and clinical characteristics of MDR bacteria

\begin{tabular}{|c|c|c|c|c|c|c|c|c|}
\hline & MSSA $(n=89)$ & MRSA $(n=68)$ & $x^{2}$ & $p$ & ECO(ESBL-) $(n=53)$ & $\mathrm{ECO}(\mathrm{ESBL}+)(n=151)$ & $x^{2}$ & $p$ \\
\hline Age & & & 2.451 & 0.484 & & & 3.871 & 0.274 \\
\hline$<20$ & 10 & 11 & & & 2 & 5 & & \\
\hline $20-39$ & 14 & 15 & & & 3 & 23 & & \\
\hline $40-59$ & 47 & 32 & & & 23 & 66 & & \\
\hline$\geq 60$ & 18 & 10 & & & 25 & 57 & & \\
\hline Gender & & & 0.077 & 0.781 & & & 0.316 & 0.574 \\
\hline Male & 65 & 51 & & & 28 & 73 & & \\
\hline Female & 24 & 17 & & & 25 & 78 & & \\
\hline Smoking $(n, \%)$ & $5(5.6)$ & $6(8.8)$ & 0.215 & 0.643 & $7(13.2)$ & $22(14.6)$ & 0.060 & 0.807 \\
\hline Alcohol (n, \%) & $7(7.9)$ & $9(13.2)$ & 1.215 & 0.270 & $6(11.3)$ & $13(8.6)$ & 0.096 & 0.757 \\
\hline Diabetes $(n, \%)$ & $6(6.7)$ & $7(10.3)$ & 0.641 & 0.424 & $7(13.2)$ & $15(9.9)$ & 0.437 & 0.509 \\
\hline Hypertension ( $n, \%)$ & $7(7.9)$ & $6(8.8)$ & 0.047 & 0.829 & $12(22.6)$ & $26(17.2)$ & 0.761 & 0.383 \\
\hline \multicolumn{9}{|l|}{ Disease entities } \\
\hline \multicolumn{9}{|l|}{ Open fracture } \\
\hline Gustillo I & 7 & 9 & 3.151 & 0.076 & 5 & 9 & 0.028 & 0.868 \\
\hline Gustillo ॥ & 7 & 8 & 2.283 & 0.131 & 4 & 9 & 0.000 & 1.000 \\
\hline Gustillo III A & 3 & 5 & 1.637 & 0.201 & 3 & 8 & 0.000 & 1.000 \\
\hline Gustillo III B & 1 & 5 & 4.178 & 0.041 & 1 & 3 & 0.069 & 0.793 \\
\hline Gustillo III C & 1 & 6 & 5.666 & 0.017 & 1 & 2 & 0.332 & 0.564 \\
\hline Degenerative disease $(n, \%)$ & $25(28.1)$ & $14(20.6)$ & 1.162 & 0.281 & $11(20.8)$ & $59(39.1)$ & 5.840 & 0.016 \\
\hline
\end{tabular}


incisional secretions, such as urine [18]. Another reason for the difference may be that the two hospitals have dissimilar disease entities. A third of the orthopedics patients in the hospital we investigated were in the trauma division, and a study carried in Sichuan province, China, found that Gram-negative bacilli were the most common isolates and that $S$. aureus was the most common Grampositive bacterium in trauma patients [19]. Finally, social, economic, and environmental variations may also account for between-study differences in different countries $[20,21]$.

Among the most widespread bacteria worldwide, E. coli is a known cause of urinary tract and bloodstream infections $[18,22]$. The antibiotic-resistance patterns of $E$. coli in this study corresponded to those in previous reports $[16,23,24]$. Taken together, the findings suggest that we should reduce the usage of antibiotics to which $E$. coli is highly resistant, such as ampicillin. Additionally, we also recommend restricted usage of third-generation cephalosporins, despite observing low resistance. Our study identified a high percentage of ESBL-producing $E$. coli, and third-generation cephalosporins are the main factors leading to the emergence and spread of these strains [25].

In the event of $E$. coli infection, we recommend cautious use of antibiotics to which the bacterium is less resistant (e.g., amikacin). Currently, many doctors use empirical antibiotics without waiting for sensitivity reports [26, 27]. Fortunately, an antibiotic with a rate of accumulated bacterial resistance below $15 \%$ should be safe for use in empiric therapy [28]. Nevertheless, during the course of our 6-year study, we observed a clear increase in resistance to imipenem and piperacillintazobactam. This outcome serves as a warning against excessive antibiotic prescription, even if the target bacteria are initially less resistant.

Staphylococcus aureus was the dominant Grampositive bacteria causing nosocomial infections in our study, in line with previous reports [29-31]. Specifically, we found high proportions of MRSA. Previous studies have similarly identified penicillin-resistant $S$. aureus [32], and indeed, our study identified only two $S$. aureus strains that were sensitive to penicillin. Furthermore, all strains were resistant to ampicillin. Together, these results indicate the real danger of MDR S. aureus. We therefore strongly advise against the empiric use of both penicillins and ampicillins. In contrast, $S$. aureus was not resistant to nitrofurantoin, linezolid, or vancomycin, suggesting that they can be safely used in clinics [33]. However, a vancomycin-resistant $S$. aureus isolate was reported in 2002, and subsequently, 14 isolates have been found in the United States [34]. Therefore, the three antibiotics should only be used in severe infections that cannot be controlled by other antibiotics. Fluoroquinolones and cotrimoxazole may be preferable, as our data show that $S$. aureus strains are not resistant to them. If neither is available, tetracycline can be a viable alternative based on the observed sensitivity of $S$. aureus to this drug [8].

Importantly, our findings clearly demonstrated a major problem with antimicrobial resistance in the study hospital, corroborating worldwide trends. Given that MDR bacteria are now recognized as a major cause of nosocomial infections [35], hospitals must work to control their incidence rate. Here, $43.3 \%$ and $74.2 \%$ of the strains were MRSA isolates and ESBL-positive E. coli, respectively, similar to a previous study in China [24]. The similarity suggests that some demographic and clinical characteristics could increase the risks of MDR bacterial infections. Indeed, we showed that patients with open fractures(Gustillo III B and IIIC) are more susceptible to MRSA infections, consequently contributing to multiple complications [36]. Regular attempts by surgeons to control infection via antibiotics likely explains the increased MDR in bacteria.

We observed a significant link between ESBLproducing $E$ coli infections and degenerative diseases, which mainly affect elderly patients. Previous studies have indicated that elderly patients are at high risk of nosocomial infections, especially from MDR bacteria $[24,37]$. This age-related risk was somewhat supported in our study, although we did not identify a significant relationship between elderly patients and MDR bacterial infections. Finally, other potential risk factors like biological sex, recreational drug use, diabetes, and hypertension did not increase the likelihood of multidrugresistant bacterial infections [38, 39].

However, our research had some limitations. First, we only analyzed the drug resistance of the major bacteria, and thus, our findings may not be fully representative of the drug resistance of the whole department. Second, we did not analyze the bacterial spectrum and drug resistance in different disease entities. Further studies are therefore required to address these issues.

\section{Conclusions}

We found that $E$ coli and $S$. aureus were, respectively, the dominant gram-negative and gram-positive bacteria responsible for nosocomial infections in orthopedics. Drug resistance patterns of these pathogens demonstrated that antimicrobial resistance remains a serious concern. Notably, doctors must be aware of the infection risk from MDR bacteria. Our results lead us to strongly advocate extensive and dynamic monitoring of MDR bacteria, along with cautious antibiotics use, to effectively control antimicrobial resistance in pathogens. 


\section{Abbreviations}

HAl: Hospital-acquired infections; ICU: Intensive care unit; MRSA: Methicillinresistant S. aureus; ESBL: Extended-spectrum $\beta$-lactamase; MDR: Multidrugresistant

\section{Acknowledgements}

Not applicable.

\section{Authors' contributions}

$\mathrm{BZ}$ and $\mathrm{RG}$ designed the experiments. $\mathrm{NH}, \mathrm{XY}$ and $\mathrm{BX}$ collected the clinical data. LW,XY and QL performed data analysis. XY and RG wrote the paper. All authors read and approved the final manuscript.

\section{Funding}

This study was supported by the Science Technology Plan of Jiangxi Provincial Health Planning Commission (20175112), Gan-Po Talents Project 555 of Jiangxi Province, Jiangxi Provincial Department of Science and Technology (20171BAB205059), Jiangxi Provincial Department of Education (GJJ160127), and Jiangxi Province Postgraduate Innovation Special Funds (YC2016-S107)

\section{Availability of data and materials}

Data are available from the corresponding author on reasonable request.

\section{Ethics approval and consent to participate}

The study protocol was approved by the Ethical Institutional Review Board of the First Affiliated Hospital of Nanchang University, and written informed consent was obtained from all study participants.

\section{Consent for publication}

Not applicable.

\section{Competing interests}

The authors declare that they have no competing interests.

\section{Author details}

'Department of Orthopedics, First Affiliated Hospital of Nanchang University, No. 17 Yong Wai Zheng Street, Nanchang 330006, Jiangxi, China. ${ }^{2}$ Department of Laboratory, First Affiliated Hospital of Nanchang University, No. 17 Yong Wai Zheng Street, Nanchang 330006, Jiangxi, China.

\section{Received: 4 November 2020 Accepted: 14 January 2021}

\section{Published online: 01 February 2021}

\section{References}

1. Weigelt JA, Lipsky BA, Tabak YP, Derby KG, Kim M, Gupta V. Surgical Site Infections: causative pathogens and associated outcomes. Am J Infect Control. 2010;38(2):112-20.

2. Stone PW, Pogorzelska-Maziarz M, Herzig CT, Weiner LM, Furuya EY, Dick A, et al. State of infection prevention in US hospitals enrolled in the National Health and Safety Network. Am J Infect Control. 2014;42(2):94-9.

3. Yang K, Han Q, Chen B, Zheng Y, Zhang K, Li Q, et al. Antimicrobial hydrogels: promising materials for medical application. Int J Nanomedicine. 2018;13:2217-63.

4. Horn SR, Liu TC, Horowitz JA, Oh C, Bortz CA, Segreto FA, et al. Clinical Impact and Economic Burden of Hospital-Acquired Conditions Following Common Surgical Procedures. Spine (Phila Pa 1976). 2018:43(22):E1358E1363.

5. Bozic KJ, Kurtz SM, Lau E, Ong K, Chiu V, Vail TP, et al. The epidemiology of revision total hip arthroplasty in the United States. J Bone Joint Surg Am. 2009:91:128-33.

6. Zheng H, Yang B, Wu X, Huang J, Zeng W, Xue Y, et al. Antibiotic susceptibility of Neisseria gonorrhoear isolates from Guangzhou, China, during 2002-2011. Jpn J Infect Dis. 2014;67:288-91.

7. Jones RN. Resistance patterns among nosocomial pathogens: trends over the past few years. Chest. 2001;119(2 Suppl):397S-404S.

8. Chen K, Huang Y, Song Q, Wu C, Chen X, Zeng L. Drug-resistance dynamics of Staphylococcus aureus between 2008 and 2014 at a tertiary teaching hospital, Jiangxi Province, China. BMC Infect Dis. 2017;17:97.
9. Tian L, Sun Z, Zhang Z. Antimicrobial resistance of pathogens causing nosocomial bloodstream infection in Hubei Province, China, from 2014 to 2016: a multicenter retrospective study. BMC Public Health. 2018;18:1121.

10. Antimicrobial resistance: global report on surveillance 2014 (WHO). Available at www.who.int/mediacentre/news/releases/2014/amr-report/en/ Accessed 30 Apr 2014.

11. Schwaber MJ, Carmeli Y. Mortality and delay in effective therapy associated with extended-spectrum beta-lactamase production in Enterobacteriaceae bacteraemia: a systematic review and meta-analysis. J Antimicrob Chemother. 2007;60(5):913-20.

12. Bastola R, Parajuli P, Neupane A, et al. Surgical site infections: Distribution studies of sample, outcome and antimicrobial susceptibility testing. J Med Microbiol Diagn. 2017:6:2161-703.

13. World Health Organization. Department of Communicable Disease, Surveillance and Response, Prevention of Hospital-acquired Infections. Geneva: World Health Organization; 2002. Publication WHO/CDS/CSR/EPH/2002.12

14. Clinical and Laboratory Standards Institute. Performance Standards for Antimicrobial Susceptibility Testing, Twenty-sixth Informational Supplement, M100-S26. Wayne: Clin Lab Stand Institute; 2016.

15. Bhardwaj N, Khurana S, Kumari M, Malhotra R, Mathur P. Pattern of antimicrobial resistance of Gram-negative bacilli in surgical site infections in in-patients and out-patients at an apex trauma Center: 2013-2016. J Lab Physicians. 2018;10(4):432-6.

16. Saravanan $R$, Raveendaran V. Antimicrobial resistance pattern in a tertiary care hospital: An observational study.J Basic. Clin Pharm. 2013:4(3):56-63.

17. Sarker MM, Saha SK, Saha SC, Naushad AN, Ajmery S, Roy P, et al. Current Trends of Using Antimicrobials and Their Sensitivity Pattern in Infectious Cases at Department of Orthopedics in a Tertiary Care Hospital. Mymensingh Med J. 2017;26(3):530-40.

18. Oli AN, Akabueze VB, Ezeudu CE, Eleje GU, Ejiofor OS, Ezebialu IU, et al. Bacteriology and Antibiogram of Urinary Tract Infection Among Female Patients in a Tertiary Health Facility in South Eastern Nigeria. Open Microbiol J. 2017;11:292-300.

19. Zhang B, Liu Z, Lin Z, Zhang X, Fu W. Microbiologic characteristics of pathogenic bacteria from hospitalized trauma patients who survived Wenchuan earthquake. Eur J Clin Microbiol Infect Dis. 2012;31(10):2529-35.

20. Vázquez GJ, Robledo IE, Arroyo A, Nadal E, Rodríguez R, Bermúdez M, et al. A comparison of the antimicrobial resistance patterns of gram-negative bacilli isolated from community-private and university-affiliated hospitals from Puerto Rico. P R Health Sci J. 2003:22(3):265-71.

21. Mao T, Zhai H, Duan G, Yang H. Patterns of Drug-Resistant Bacteria in a General Hospital, China, 2011-2016. Pol J Microbiol. 2019;68(2):225-32.

22. Harris PNA, Tambyah PA, Lye DC, Mo Y, Lee TH, Yilmaz M, et al. Effect of Piperacillin-Tazobactam vs Meropenem on 30-Day Mortality for Patients With E coli or Klebsiella pneumoniae Bloodstream Infection and Ceftriaxone Resistance: A Randomized Clinical Trial. JAMA. 2018;320(10):984-94.

23. Umadevi S, Kandhakumari G, Joseph NM, et al. Prevalence and antimicrobial susceptibility pattern of ESBL producing gram negative bacilli. J Clin Diagn Res. 2011:5:236-9.

24. Wang M, Wei H, Zhao $Y$, Shang L, Di L, Lyu C. et al.Analysis of multidrugresistant bacteria in 3223 patients with hospital-acquired infections (HAl) from a tertiary general hospital in China. Bosn J Basic Med Sci. 2019:19(1):86-93.

25. Manzur A, Tubau F, Pujol M, Calatayud L, Dominguez MA, Pena C, et al. Nosocomial outbreak due to extended-spectrum-beta-lactamase-producing Enterobacter cloacae in a cardiothoracic intensive care unit. J Clin Microbiol. 2007;45(8):2365-9.

26. Jamshidi M, Javadpour S, Eftekhari TE, et al. Antimicrobial resistance pattern among intensive care unit patients. Afr J Microbiol Res. 2009;3:590-4.

27. Saravanan R, Arun Muthukumar GL. A surveillance study of antibiotic use in Pondicherry-2012. Int J Basic Clin Pharmacol. 2012;1:202-10.

28. Andreu A, Alós Jl, Gobernado ME, Marco F, de la Rosa M, Garcia-Rodriguez JA, et al. Etiology and antimicrobial susceptibility among uropathogens causing community-acquired lower urinary tract infections: a nationwide surveillance study. Enferm Infecc Microbiol Clin. 2005;23(1):4-9.

29. Kim ES, Kim HB, Kim G, Kim KH, Park KH, Lee S, et al. Clinical and epidemiological factors associated with methicillin resistance in communityonset invasive Staphylococcus aureus infections: prospective multicenter cross-sectional study in Korea. PLoS One. 2014;9:e114127.

30. Roberts S, Chambers S. Diagnosis and management of Staphylococcus aureus infections of the skin and soft tissue. Intern Med J. 2005;35(s2):S97-S105. 
31. Sader HS, Mendes RE, Pfaller MA, Flamm RK. Antimicrobial activity of dalbavancin tested against Gram-positive organisms isolated from patients with infective endocarditis in US and European medical centres. J Antimicrob Chemother. 2019;74(5):1306-10.

32. Rammelkamp CH, Maxon T. Resistance of Staphylococcus aureus to the action of penicillin. Exp Biol Med. 1942;51(3):386-69.

33. Khurana S, Mathur P, Malhotra R. Staphylococcus aureus at an Indian tertiary hospital: Antimicrobial susceptibility and minimum inhibitory concentration (MIC) creep of antimicrobial agents. J Glob Antimicrob Resist. 2019;17: 98-102.

34. Walters MS, Eggers P, Albrecht V, Travis T, Lonsway D, Hovan G, et al. Vancomycin-resistant Staphylococcus aureus-Delaware, 2015. MMWR Morb Mortal Wkly Rep. 2015;64(37):1056.

35. Bubonja-Sonje M, Matovina M, Skrobonja I, Bedenic B, Abram M. Mechanisms of carbapenem resistance in multidrug-resistant clinical isolates of Pseudomonas aeruginosa from a Croatian hospital. Microb Drug Resist. 2015;21(3):261-9.

36. Carver DC, Kuehn SB, Weinlein JC. Role of systemic and local antibiotics in the treatment of open fractures. Orthop Clin North Am. 2017;48(2):137-53.

37. Ruscher C, Pfeifer $Y$, Layer F, Schaumann R, Levin $K$, Mielke M. Inguinal skin colonization with multidrug-resistant bacteria among residents of elderly care facilities: Frequency, persistence, molecular analysis and clinical impact. Int J Med Microbiol. 2014;304(8):1123-34.

38. Valderrama-Beltrán S, Gualtero S, Álvarez-Moreno C, Gil F, Ruiz AJ, Rodríguez $J Y$, et al. Risk factors associated with methicillin-resistant Staphylococcus aureus skin and soft tissue infections in hospitalized patients in Colombia. Int J Infect Dis. 2019;87:60-6.

39. Gómez-Gómez A, Magaña-Aquino M, López-Meza S, Aranda-Álvarez M, Díaz-Ornelas DE, Hernández-Segura MG, et al. Diabetes and Other Risk Factors for Multi-drug Resistant Tuberculosis in a Mexican Population with Pulmonary Tuberculosis: Case Control Study. Arch Med Res. 2015 46(2):142-8.

\section{Publisher's Note}

Springer Nature remains neutral with regard to jurisdictional claims in published maps and institutional affiliations.

Ready to submit your research? Choose BMC and benefit from:

- fast, convenient online submission

- thorough peer review by experienced researchers in your field

- rapid publication on acceptance

- support for research data, including large and complex data types

- gold Open Access which fosters wider collaboration and increased citations

- maximum visibility for your research: over $100 \mathrm{M}$ website views per year

At $\mathrm{BMC}$, research is always in progress.

Learn more biomedcentral.com/submissions 